\title{
Endobronchial ultrasound-guided transbronchial fine needle aspiration: advantages and potential pitfalls
}

This article was published in the following Dove Press journal:

Pathology and Laboratory Medicine International

14 October 2015

Number of times this article has been viewed

\author{
Heidi H Hamilton' \\ Jalidsa Pellicier' \\ Matthew Bernstein' \\ Haytham Dimashkieh² \\ Jack Yang' \\ 'Department of Pathology and \\ Laboratory Medicine, Medical \\ University of South Carolina, \\ Charleston, ${ }^{2}$ Department of Pathology, \\ Greenville Memorial Hospital, \\ Greenville, SC, USA
}

\begin{abstract}
Endobronchial ultrasound-guided fine needle aspiration (EBUS-FNA) is currently considered the procedure of choice for evaluating mediastinal and hilar lymph nodes in patients with non-small-cell lung carcinoma. In this setting, it is a minimally invasive procedure that can be used to simultaneously diagnose, stage, and obtain cellular material for ancillary studies. Additionally, EBUS-FNA can also be used to triage and diagnose many other mediastinal pathologic processes, such as metastatic malignancy from nonpulmonary origins, lymphoma, and granulomatous lymphadenopathy. At a time when EBUS-FNA is considered the optimal choice for many neoplastic and nonneoplastic conditions of the mediastinal lymph nodes, it has become increasingly important for pathologists to familiarize themselves with the nuances of this procedure. The primary focus of this review is to explore the advantages, adequacy issues, and potential pitfalls of EBUS-FNA, paying particular attention to the situations that may adversely affect patient management.
\end{abstract}

Keywords: lung cancer staging, cytology, mediastinal lymph node

\section{Introduction}

Lung cancer is the most common cancer and the leading cause of cancer death worldwide. ${ }^{1,2}$ The treatment and prognosis of patients with lung cancer, especially non-small-cell lung cancer (NSCLC) are dependent on accurate staging. Currently, the tumor-lymph node-metastasis (TNM) classification scheme by The Union Internationale Contre le Cancer (UICC) and the American Joint Committee on Cancer (AJCC) is the most widely accepted method for staging NSCLC. ${ }^{3}$ It is based on the size and location of the tumor, status of mediastinal lymph nodes, and distant metastasis. Among these criteria, the evaluation of mediastinal lymph node involvement is probably the most challenging. Over the years, many methods have been used to accomplish this goal, which include imaging (computed tomography and positron emission tomography [PET] scans), mediastinoscopy-guided biopsy, video-assisted thoracic surgical biopsy, traditional transbronchial biopsy, and, most recently, endobronchial ultrasound-guided fine needle aspiration (EBUS-FNA).

The utility of EBUS-FNA in the evaluation of hilar and mediastinal lymph nodes in patients with NSCLC started in the mid-1990s. ${ }^{4}$ It did not take long for EBUS-FNA to be accepted as the procedure of choice for this purpose. In the proper clinical settings, EBUS-FNA can be used to simultaneously diagnose, stage, and obtain cellular material for ancillary tests, including molecular analysis for prognosis and targeted therapy. Numerous studies have demonstrated that EBUS-FNA is an accurate, minimally invasive, and cost-effective procedure for the staging of mediastinal lymph nodes
Department of Pathology and Laboratory

Medicine, Medical University of South

Carolina, I7I Ashley Avenue,

MSC 908, Charleston, SC 29425, USA

Tel +l 8437928423

Fax+l 8437928974

Email yangja@musc.edu 
when compared with other methods, including mediastinoscopy, which was previously considered the gold standard. ${ }^{5-10}$ The most recently updated guidelines of both the American College of Chest Physicians and the European Society of Thoracic Surgeons now recommend EBUS-FNA over other methods in the staging of NSCLC. ${ }^{11,12}$

\section{Staging of NSCLC}

Staging is a critical part of the evaluation of every patient with lung cancer. The current seventh edition of the lung cancer staging system was based on a major initiative undertaken by the International Association for the Study of Lung Cancer, in which lung cancer is staged according to the size of primary tumor, regional lymph node status, and distance metastasis. ${ }^{3,13}$ In the absence of clinical and radiological evidence of distant metastasis, the evaluation of regional lymph node involvement becomes particularly critical in lung cancer staging, because in many cases, the status of these nodes determines whether there is surgically resectable disease. Regional lymph nodes, ie, mediastinal lymph nodes, are grouped into zones as follows: a supraclavicular zone (station 1), an upper zone (stations 2-4), an aortopulmonary zone (stations 5 and 6), a subcarinal zone (station 7), a lower zone (stations 8 and 9), a hilar zone (stations 10 and 11), and a peripheral zone (stations $12-14) .{ }^{14}$ Figure 1 shows the regional lymph node classification for lung cancer staging adopted from the American Thoracic Society mapping scheme.

Clinical staging of NSCLC is usually directed by noninvasive imaging modalities. ${ }^{11,15}$ On the basis of such tests, physicians determine the likelihood of the presence or absence of tumor involvement in regional lymph nodes. In general, patients with lung cancer can be separated into four groups with respect to intrathoracic radiographic characteristics, including both the primary tumor and the mediastinum. The first group involves patients with mediastinal infiltration that encircles the vessels and airways, so that discrete lymph nodes can no longer be discerned or measured. In these situations, the presence of mediastinal involvement (stage III) is generally accepted based on imaging alone. The second group involves patients with mediastinal node enlargement (defined as a short-axis diameter of $\geq 1 \mathrm{~cm}$ ). In these patients, mediastinal nodal involvement is suspected but must be confirmed. The third group involves patients with mediastinal nodes that are not enlarged; however, the presence of a central tumor or suspected N1 disease makes the chance of N2, N3 nodal involvement relatively high, and further confirmation is needed. The final group involves those with a peripheral clinical stage I tumor and the chance of mediastinal involvement is quite low, and, generally, further confirmation is not needed. ${ }^{11}$

Further evaluation of mediastinal involvement usually requires obtaining tissue for purposes of diagnosis and molecular analysis of the tumor. Several methods are commonly used in obtaining the tissue: mediastinoscopyguided biopsy, video-assisted thoracic surgical biopsy, traditional transbronchial biopsy/FNA, and more recently, endoscopic ultrasound (EUS) and EBUS-FNA.

Mediastinal assessment by mediastinoscopy is the most accurate method to establish the clinical $\mathrm{N}$ stage and has been used for $>50$ years. ${ }^{14,16,17}$ In this procedure, a mediastinoscope is inserted through an incision at the suprasternal level of a

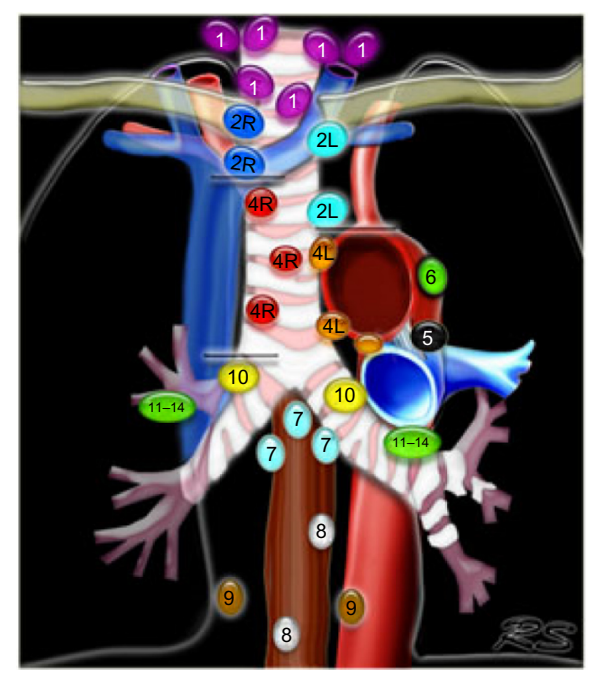

\section{Mediastinal lymph node map \\ Supraclavicular nodes: level 1 \\ Superior mediastinal nodes: levels 2-6 \\ Aortic nodes: levels 5 and 6 \\ Inferior mediastinal nodes: levels 7-9 \\ Hilar and lobar segmental nodes: levels 10-14}

Lymph node staging of lung cancer

NO: No lymph node metastasis

N1: Metastasis in ipsilateral levels 10-14

N2: Metastasis in ipsilateral levels 2-9

N3: Metastasis in level 1 or any contralateral node

Figure I Regional lymph node classification for lung cancer staging.

Notes: Adapted from Smithius R. IASLC lymph node map 2009. Radiology Assistant. Available at: http://www.radiologyassistant.nl/en/p4646fl278c26f/mediastinum-lymphnode-map.html. Accessed May 7, 2015. ${ }^{103}$ 
patient under general anesthesia. Mediastinal lymph nodes are dissected and at least one node biopsy sample is taken from each station. Mediastinoscopy provides good access to stations 2 and 4 and the upper anterior part of station 7 . A systematic review of surgical mediastinoscopy in patients with NSCLC reported a sensitivity of $81 \%(40 \%-97 \%)$ and a negative predictive value (NPV) of 91\% $(86 \%-99 \%) .{ }^{11}$ Videoassisted thoracic surgery (VATS) is similar to mediastinoscopy and aims to remove all tissues containing mediastinal lymph nodes. Access to lymph node stations 5 and 6, which cannot be routinely accessed by either cervical mediastinoscopy or EBUS, is best provided by VATS. The disadvantages of mediastinoscopy and VATS include the need for general anesthesia, the risk of nerve injury, and substantial morbidity and mortality. In addition, they are difficult to perform during restaging after radiation induction treatment due to scar formation.

EBUS was developed and applied for diagnostic purposes in the early 1990s. ${ }^{18,19}$ It incorporates an ultrasound probe at the end of a flexible bronchoscope. There are two types of ultrasound probes available: the radial and the convex (also called linear) probe. The radial probe, with an inflatable water balloon that couples the ultrasound probe to the tracheobronchial wall, passes through the working channel of a flexible bronchoscope and provides a $360^{\circ}$ ultrasonographic image of the surrounding structures with a depth up to $5 \mathrm{~cm}$ (Figure 2). It has only limited use in EBUS-FNA because there is no needle attached to the device. In order to perform FNA, the operator needs to mark the site and remove the ultrasound probe from the bronchoscope before introducing a needle for the FNA biopsy. Therefore, EBUS-FNA with a radial probe

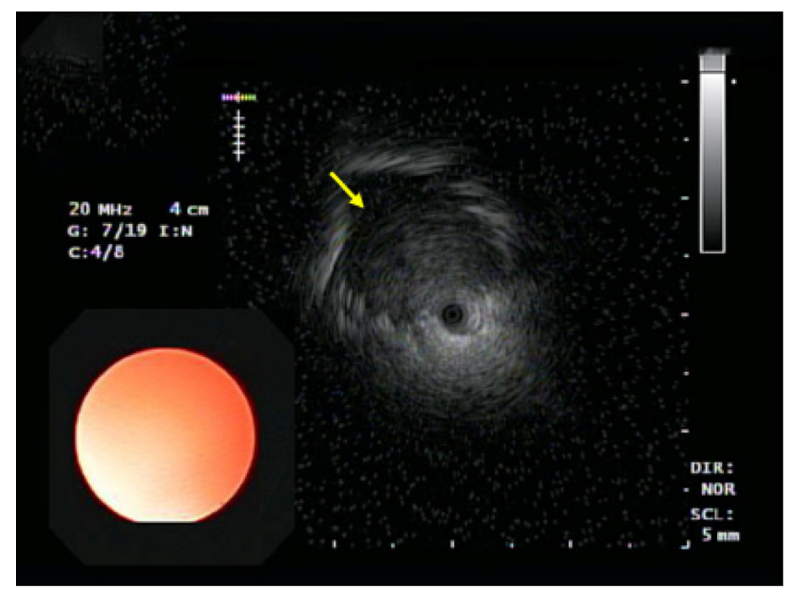

Figure 2 Image with a radial endobronchial ultrasound probe.

Notes: A $360^{\circ}$ ultrasonographic view of the area surrounding the bronchium. A large irregular-shaped mass lesion can be seen in the area indicated by the arrow. The circular area in the left lower corner shows a view (out of focus) from the bronchoscope. Figure courtesy of Dr Nicholas J Pastis, Department of Medicine, Medical University of South Carolina, SC, USA. is a sequential sampling process, not a real-time one. The convex probe, a newly developed and more commonly used one, is attached to the end of a dedicated flexible bronchoscope and coupled with a special needle, thus allowing real-time visualization during the needle puncture of parabronchial structures (Figure 3). The convex ultrasound probe provides a $60^{\circ}$ forward oblique view and obtains images at a depth of penetration of up to $9 \mathrm{~cm}$. A dedicated, special 19-gauge to 25-guage needle is used to perform the FNA, which can protrude up to $4 \mathrm{~cm}$ (Figure 3). EBUS allows access to mediastinal lymph nodes $2 \mathrm{R}, 2 \mathrm{~L}, 3 \mathrm{P}, 4 \mathrm{R}, 4 \mathrm{~L}$, and 7, as well as hilar nodes 10R, 10L, 11R, and 11L. ${ }^{4,20}$

EBUS-FNA has similar accuracy in diagnosing and staging lung cancer as mediastinoscopy and VATS. General anesthesia is usually not required and complications are much less frequent. In cases of restaging, it is not affected by structural alteration induced by radiation therapy. 5,7,21,22 The sensitivity, specificity, positive predictive value (PPV), and NPV of EBUS in diagnosing and staging NSCLC were 46-89\% (median 89\%), 96-100\% (median 100\%), 93-100\% (median 100\%), and 60-99\% (median 91\%), respectively. ${ }^{11}$

EBUS-FNA has also been used in restaging lung cancer after chemoradiation therapy. Although most of the studies indicated that it was an effective tool in this setting, controversial studies also exist. ${ }^{22-27}$ The study by Anraku et $\mathrm{al}^{22}$ showed that the sensitivity, specificity, and diagnostic accuracy of EBUS-FNA in restaging lung cancer were $93.1 \%, 100 \%$, and $95.1 \%$, respectively. In the study by Herth et al, ${ }^{25}$ overall sensitivity, specificity, PPV, NPV, and

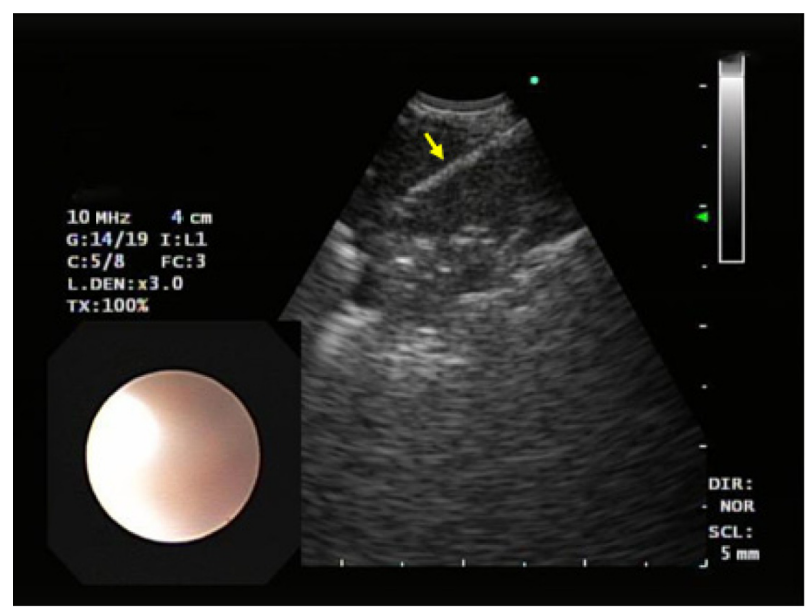

Figure 3 Image with a convex/linear endobronchial ultrasound probe.

Notes: The green dot indicates the needle entry point. The needle (arrow) movement can be captured in real time. The circular area in the left lower corner shows a view (out of focus) from the bronchoscope. Figure courtesy of Dr Nicholas J Pastis, Department of Medicine, Medical University of South Carolina, SC, USA. 
diagnostic accuracy of EBUS-FNA for mediastinal restaging after induction chemotherapy were $76 \%, 100 \%, 100 \%$, $20 \%$, and $77 \%$, respectively. The study by von Bartheld et $\mathrm{al}^{23}$ concluded that this technique has a low NPV and is not useful for the exclusion of mediastinal metastases for restaging purposes.

Tumor tissue acquisition for mutation analysis has been becoming a pressing need for prognosis and treatment options. ${ }^{28,29}$ Studies have shown that EBUS-FNA can be used to obtain sufficient cellular material for molecular analysis. ${ }^{30-32}$ Tumor DNA could be extracted from the designated solutions, glass slides, and cell blocks containing ideally $40 \%$ tumor cells. ${ }^{33,34}$ In a study by Nakajima et al, ${ }^{32}$ a portion of each needle pass was collected into a solution for DNA extraction, and epidermal growth factor receptor (EGFR) mutation analysis was successfully performed on 154 of $156(98.7 \%)$ cases. Similar successful rate (96 of 99 cases) of EGFR and Kirsten rat sarcoma viral oncogene homolog (Kras) mutation testing using the tumor cells scraped from the glass slides was reported by Billah et al. ${ }^{33}$ Fluorescence in situ hybridization analysis for anaplastic lymphoma kinase $(A L K)$ gene rearrangements was also performed with a high rate of success. ${ }^{35}$

\section{Evaluation of mediastinal lymphadenopathy of other etiology}

EBUS has also been used in the diagnosing and triaging of many other mediastinal lymphadenopathies, such as metastatic malignancy from nonpulmonary origins, lymphoma, and granulomatous lymphadenitis. ${ }^{36-39}$ A systematic meta-analysis of 533 patients from six studies showed that the pooled sensitivity and specificity of EBUS-FNA in detecting metastases from extrathoracic malignancies were $85 \%$ (95\% confidence interval [CI]: 0.80-0.89) and 99\% (95\% CI: 0.95-1.00), respectively. ${ }^{40}$ Diagnosis of lymphoproliferative disorders, especially low-grade lymphomas, in cytological preparation has been challenging. It often requires detailed clinical information and sufficient material for ancillary studies in order to obtain accurate diagnosis and classification. ${ }^{41}$ Results from a study by the College of American Pathologists Interlaboratory Comparison Program ${ }^{42}$ have shown that based on cytomorphology alone, approximately $87 \%$ of Hodgkin lymphoma and $68 \%$ of non-Hodgkin lymphoma (predominantly large cell lymphoma) cases could be correctly identified. In a study on EBUS-FNA in the diagnosis of mediastinal lymphoproliferative disorders, it was found that aspirates from 31 of 34 patients clinically suspected of lymphoma were adequate for diagnosis, and among them, 23 had enough material for ancillary tests, such as flow cytometry and immunocytochemical studies. All eight lymphoma cases were correctly diagnosed in this study. ${ }^{43}$ EBUS-FNA has been widely used in confirmation of clinically suspected sarcoidosis with pulmonary and mediastinal involvement. Numerous studies have shown that EBUS-FNA is a safe and efficacious procedure in the diagnosis of sarcoidosis. ${ }^{44-48}$ A systematic review and meta-analysis by Agarwal et al, ${ }^{49}$ which included 553 patients from 15 studies, shown that the diagnostic yield of EBUS-FNA ranged from 54\%-93\%, with the pooled diagnostic accuracy being 79\% (95\% CI: $71 \%-86 \%$ ).

The advantages and clinical application of EBUS-FNA have been extensively reviewed in the literature. ${ }^{4,20,50-54}$ The primary focus of this review will be to explore the potential pitfalls that may occur during EBUS-FNA, with a specific focus on the ones that may adversely affect patient management.

\section{Sample adequacy}

An adequate sample is essential for an accurate cytologic diagnosis. In cases of NSCLC, this includes obtaining sufficient material for both diagnosis and molecular analysis. The criteria for adequacy are complicated, especially in the absence of tumor cells. It would depend on many factors, including the number of lymphocytes present, the size of the lymph node, and the clinical suspicion, among others. Although many studies have indicated that inadequate sampling is what contributed to most of the false-negative cases, only a few studies have attempted to address the issue regarding the sample adequacy in transbronchial FNA. The study by Baker et $\mathrm{al}^{55}$ was among the first to define sample adequacy of transbronchial FNA. Using the presence or absence of lymphocytes as an essential adequacy criterion, it was found that the NPV was $78 \%$ for nonmalignant aspirates containing lymphocytes and $36 \%$ for nonmalignant aspirates not containing lymphocytes. ${ }^{55}$ This criterion has been used in many other studies without further defining the number of lymphocytes required. ${ }^{56,57}$ In a study of EUS-FNA by Kramer et al, ${ }^{58}$ a lymph node aspirate was considered insufficient for diagnosis (unsatisfactory) if at least one of the smears did not contain an area with many small lymphocytes and/or follicle center cells. According to this criterion, 55 out of 155 (35\%) of the aspirates were unsatisfactory. Among these 55 cases, 30 were proven to be positive for malignancy by other means in comparison with the cases with negative cytologic diagnosis in which three of 13 cases were positive for malignancy. It is, however, 
obvious that an unsatisfactory rate of $35 \%$ of FNA is far too high in routine practice. Furthermore, a study by Skov et al, ${ }^{59}$ which used the aforementioned criterion showed the same (35\%) unsatisfactory rate and, in addition, greater inter- and intra-observer variability among the pathologists involved in the study. Nayak et $\mathrm{al}^{60}$ proposed an adequacy criterion that any smear with the presence of $>5$ low-power fields $(\times 100)$ with $\geq 100$ lymphocytes in each and containing $<2$ groups of bronchial cells per low-power field $(\times 100)$ could be considered adequate for evaluation. In addition, the presence of germinal center fragments rendered a smear adequate for evaluation, irrespective of the aforementioned criteria. ${ }^{60}$ The major flaw of the study was that there were no positive cases identified in the follow-up of the patients with unsatisfactory cytology; therefore, the benefits of sample adequacy could not be meaningfully evaluated. A study by Alsharif et $\mathrm{al}^{9}$ used " $\geq 40$ lymphocytes/HPF $(\times 400)$ in the most cellular areas of the slide" as their adequacy criterion and found that four of ten cases with unsatisfactory cytology were proven to be positive during the follow-up. In comparison, only one of 48 cases with negative cytologic diagnosis was positive. ${ }^{9}$ Using the same criteria, a study by Karunamurthy et $\mathrm{al}^{61}$ showed that seven of 30 cases of unsatisfactory and six of 55 cases with negative cytologic diagnosis were positive in follow-up. The requirement of 40 or more lymphocytes has been used in other studies as well. ${ }^{8,62}$

Overall, there is no one criterion that fits all situations. The evaluation of sample adequacy should take into consideration the clinical, radiological, and cytological findings. For example, a negative cytologic diagnosis on a clinically suspicious large PET-positive lymph node should be made with caution despite the presence of an "adequate" number of lymphocytes. In the majority of these situations, clinicians often repeat FNA or use another modality such as mediastinoscopy for further evaluation despite the negative cytologic diagnosis. Furthermore, in the era of targeted therapy, the evaluation of adequacy may have to also take into consideration the amount of material available for mutation analysis. ${ }^{63,64}$

\section{Rapid on-site evaluation}

Although the utility of rapid on-site evaluation (ROSE) during EBUS-FNA for lymph node staging in lung cancer is still controversial, most of the studies have shown that the benefits of ROSE outweigh the drawbacks in EBUS-FNA. ${ }^{20,65-71}$ ROSE provides an opportunity for cytopathologists to interact with pulmonologists and thoracic surgeons, who are able to provide detailed clinical and imaging information about the patients, so that a more focused examination can be performed. Studies have shown that ROSE improves the sample adequacy rate and diagnostic yield. An early study by Davenport ${ }^{56}$ demonstrated that ROSE produced a significant increase in the percentage of specimens containing malignant cells, from $31 \%$ to $56 \%$, and a large decrease in the percentage of specimens that were inadequate for diagnosis, from $56 \%$ to $18 \%$. The utility of ROSE has shown reduction in the number of needle passes and the sites biopsied because it may not be necessary to biopsy lymph node if a higher-stage lymph node is positive for malignant cells by on-site evaluation. In a study by Collins et al, ${ }^{66}$ a matched cohort of 340 patients ( 680 total) for each category of non-ROSE and ROSE services were evaluated, and the results showed that there was a $33 \%$ reduction in the number of sites biopsied with ROSE; a total of $68 \%$ of patients with ROSE had just one biopsy site compared to only $36 \%$ of non-ROSE patients, and there was a $30 \%$ decrease in total slides after the introduction of ROSE. All of these improvements were statistically significant. ${ }^{66}$ ROSE is essential for triaging and utilizing the sample efficiently. Ideally, only a small portion of each pass should be used for making smears and the remaining material should be saved for making a cell block or performing ancillary tests. The potential advantage of this is that what is seen on the slide would likely be representative of the material in the cell block or the sample for other tests, such as flow cytometry. It is expected that ROSE will play a more important role in ensuring an adequate sample for ancillary tests, such as immunocytochemical and molecular analyses.

Despite the aforementioned advantages, the utility of ROSE is not without demerits. It generally requires the physical presence of a cytologist on site to prepare and evaluate the slides. This may be especially challenging in smaller institutions that lack dedicated resources. No significant difference was found with and without ROSE in terms of diagnostic yield, sample adequacy rate, number of passes, and procedure duration in some studies. ${ }^{69,72}$ In addition, ROSE services performed by cytopathologists are compensated insufficiently by current Medicare compensation schedules in the USA. ${ }^{73}$ This has led to the development of alternatives, such as using a cytotechnologist or a trained pulmonologist to prepare and read the specimen ${ }^{74,75}$ and telecytopathology. ${ }^{76-78}$

A systematic review and meta-analysis based on highquality studies with head-to-head comparisons of two cohorts (with and without ROSE) showed that on average, ROSE improved the adequacy rate by $12 \%$, but there was considerable 
variability across studies and the adequacy rate with ROSE depended on the non-ROSE adequacy rate. ${ }^{71}$ A significant improvement in sample adequacy rate with ROSE was typically seen in the studies where the non-ROSE adequacy rate was low. ROSE may not be needed in an institution where a sample adequacy rate for EBUS-FNA is $>90 \%$. Future sample adequacy assessment, however, will likely require sufficient material for ancillary tests in which ROSE plays an important role. A recent study ${ }^{79}$ concluded that ROSE might prevent the need for a repeat invasive diagnostic procedure aimed at molecular profiling in at least one out of ten patients with advanced lung cancer, in addition to significantly reducing the risk of retrieving samples that can only be used for pathologic subtyping due to minimal tumor burden. ROSE is also especially valuable to pulmonologists who are undergoing training in EBUS-FNA procedure. ${ }^{80}$

One of the major concerns is that the preliminary diagnosis given at the time of ROSE may not always correlate with the final diagnosis, and sometimes, it is incorrect. Therefore, it has to be emphasized that clinical management of a patient should never be based on the preliminary diagnosis made based on ROSE alone. Some potential pitfalls in EBUS-FNA that may affect interpretation, especially at ROSE, are discussed later.

\section{Benign bronchial epithelial cell contaminants}

Reactive bronchial epithelial cells, reserve cells, metaplastic squamous cells, and submucosal glandular cells can be seen in EBUS-FNA samples and usually do not pose a significant problem for cytologic diagnosis. However, they do occasionally pose challenge in some cases, especially at the time of ROSE.

The hallmarks of benign bronchial epithelial cells are the presence of cilia (even though extremely rare cases of ciliated adenocarcinomas of the lung have been reported ${ }^{81}$ ), terminal bars, and admixed goblet cells. Therefore, the presence of these features usually indicates benignancy regardless of the degree of cellular atypia. Under certain circumstances, such as a long history of smoking, mechanical stimulation, and chemoradiation therapy, the cells can show exuberant reactive atypia and the aforementioned benign cellular features may be focally absent or overlooked. ${ }^{9,57,67,78,82,83}$ Significant nuclear enlargement, nuclear pleomorphism, irregular nuclear membranes, and prominent nucleoli can be seen in these reactive bronchial epithelial cells. This is especially problematic in patients treated with chemotherapy and radiation before EBUS-FNA (Figure 4).

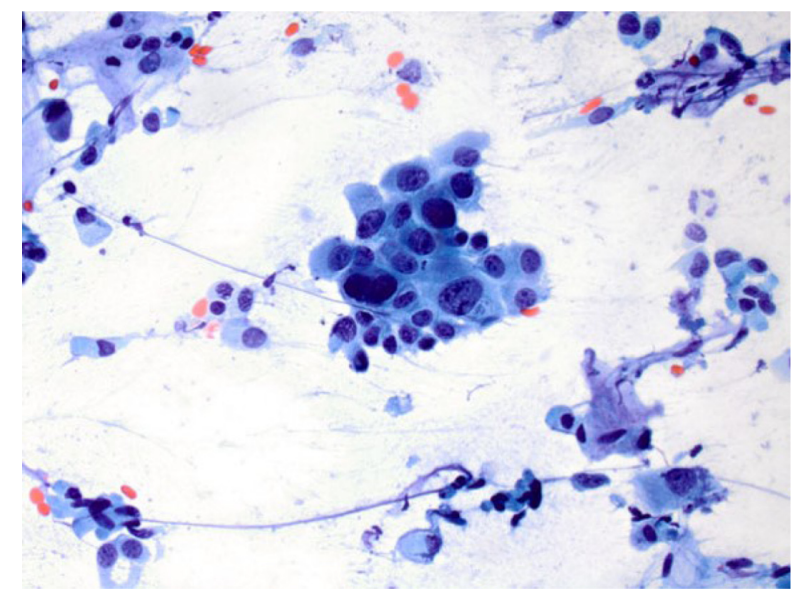

Figure 4 Bronchial epithelial cells with radiation atypia.

Notes: The cells show a spectrum of changes ranging from obviously recognizable benign to highly atypical morphology. Note the terminal bar is visible in some of highly atypical cells.

Careful inspection for the presence of cilia and comparison of the nuclei of pertinent cells to those of obviously benign cells are essential. Reactive bronchial epithelial cells, especially in response to chemoradiation, often show a spectrum of changes instead of distinct populations of cells as seen in cases of malignancy. Respiratory reserve cells can also be seen in transbronchial FNA. They appear as groups of small cells with scant cytoplasm and hyperchromatic nuclei, and usually, they are closely associated with ciliated respiratory cells (Figure 5). In cases of reserve cell hyperplasia, however, the cells can be present in large numbers and morphologically mimic neoplastic cells, especially small cell carcinoma and basaloid squamous cell carcinoma. Unlike small cell carcinoma, respiratory reserve cells have smooth nuclear

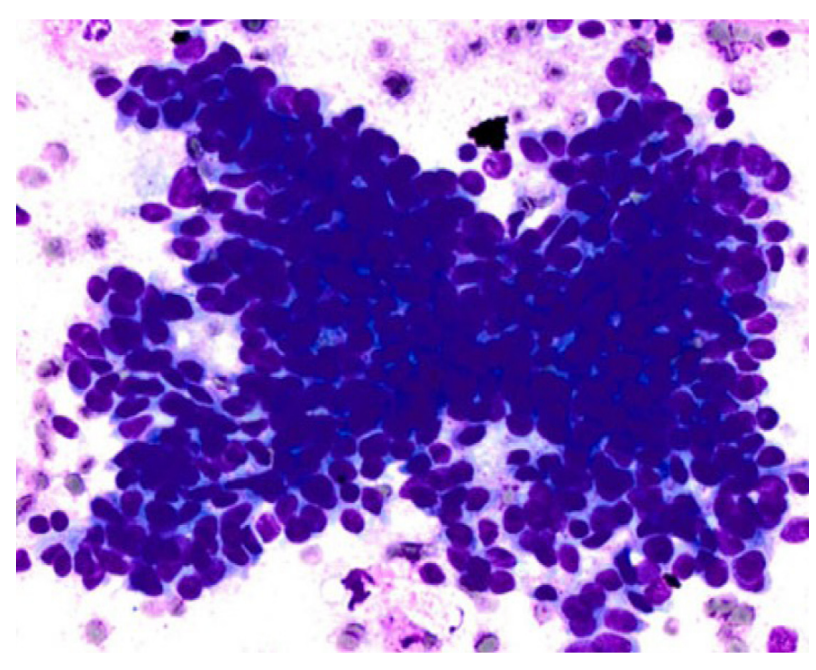

Figure 5 Bronchial reserve cell hyperplasia.

Note: The reserve cells appear as groups of small cells with scant cytoplasm and hyperchromatic nuclei, closely associated with ciliated respiratory cells. 
membranes and fine chromatin, and they do not usually show crushing artifact and necrosis. It is worthwhile to note that respiratory reserve cells can be immunologically reactive to TTF-1, CK5/6, p63, and p40 ${ }^{84}$ therefore, caution should be taken in interpreting immunocytochemical stains in cases of reserve cell hyperplasia. In patients with a long history of smoking, bronchial epithelial cells can undergo squamous metaplastic and dysplastic changes, which have been known to cause significant problems in transbronchial FNA. Under these circumstances, it is important to correlate the clinical information and bronchoscopic findings and carefully examine the samples for other clues, such as necrosis. Submucosal glandular cells can occasionally present as small groups of epithelioid cells with granular or clear cytoplasm, which may mimic carcinoid tumor or metastatic malignancy, especially renal cell carcinoma (Figure 6).

\section{Granuloma (necrotizing/ nonnecrotizing granulomas and granuloma in malignancy)}

Granulomatous inflammation is one of the common causes of mediastinal lymphadenopathy. Morphologically, it is characterized by the presence of aggregates of epithelioid histiocytes, lymphocytes, and multinucleated giant cells. A necrotizing/caseating granuloma can be cytologically diagnosed when finely granular amorphous necrotic debris is present in the background, which usually indicates an infectious etiology, such as a fungal or mycobacterial infection. Due to the sampling issue, however, it is still in debate whether a nonnecrotizing/epithelioid granuloma, which usually indicates sarcoidosis and other

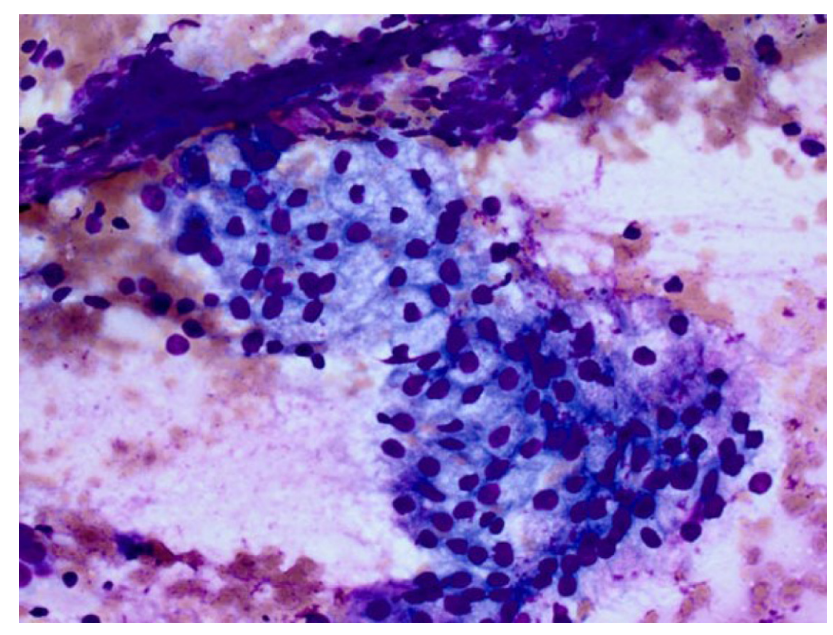

Figure 6 Submucosal glandular cells.

Note: Groups of submucosal minor salivary glandular cells with bland nuclei, fine vacuolated cytoplasm, mostly in acinar configuration. noninfectious etiologies, can be reliably diagnosed on cytology material. ${ }^{85,86}$ A study by Gailey et al $^{86}$ indicated that in the majority of cases, histoplasmosis and sarcoidosis can be separated based on several cytologic features: the presence or absence of necrosis, the number of granulomas per slide, the morphologic character of the granulomas, the presence or absence of acute inflammatory cells in the infiltrate, the presence or absence of giant cell infiltrates, and the type of giant cells. It is worth noting that $36 \%$ of granulomas with histoplasmosis did not show significant necrosis on cytological preparation. ${ }^{86}$ Furthermore, rare but significant - number of sarcoidosis instances may present as necrotizing granulomas. ${ }^{87}$ Therefore, special staining procedures and microbiological cultures should be performed on all granulomatous inflammation regardless of the presence of necrotic debris. It is important to keep in mind that granulomas can occur in malignancy as well. ${ }^{44,88} \mathrm{It}$ is well known that granulomas can be present in lymphoma, especially Hodgkin lymphoma. ${ }^{89}$ Keratin debris in squamous cell carcinoma, mucin produced by adenocarcinoma, and others can also elicit granulomatous reactions (Figure 7). ${ }^{90-94}$ Therefore, it is essential to carefully examine the slides in cases of granuloma to rule out coexisting malignancy.

\section{Small cell carcinoma and basaloid squamous cell carcinoma}

Small cell carcinoma and basaloid squamous cell carcinoma may share similar clinical and cytological morphology in some cases. ${ }^{78,95-97}$ Lymph node metastases from basaloid squamous carcinoma were frequently misdiagnosed as small cell carcinoma. Due to the potential difference in clinical management, it is important to distinguish them from

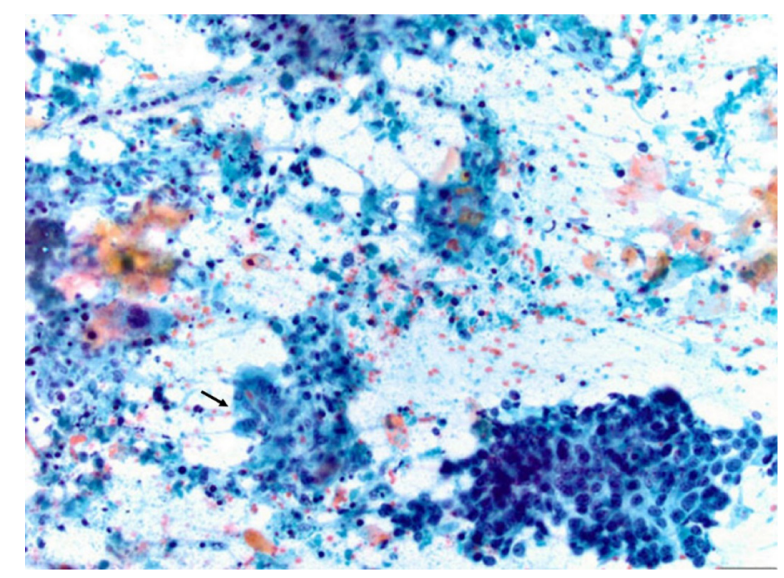

Figure 7 Granuloma associated with squamous cell carcinoma.

Note: A small aggregate of epithelioid histiocytes (arrow) is present in a background of tumor cells and necrotic debris. 
each other. In general, both tumors are composed of small neoplastic cells with hyperchromatic chromatin and scant cytoplasm, and nuclear crowding and necrosis are commonly seen in both. The presence of prominent nucleoli and peripheral palisading usually favor basaloid squamous cell carcinoma. Crushing artifact, nuclear molding, and apoptosis are more commonly seen in small cell carcinoma. In rare cases, immunocytochemical studies may be required for a definitive diagnosis. Basaloid squamous cell carcinoma is positive for $\mathrm{CK} 5 / 6$, p63, and p40, apart from being negative for neuroendocrine markers. In addition, lymphocytes, especially obtained with a large-gauge needle, can present as cohesive-appearing tissue fragments (Figure 8), which can mimic small cell carcinoma and basaloid squamous cell carcinoma, especially on Diff-Quik-stained slides. Comparing the cells breaking off from fragment edges with the background lymphocytes should provide the clues in identifying the cells that make up the fragments. Again, immunocytochemical studies on cell block material would be able to provide definitive evidence of lymphoid tissue.

\section{Lymphoma}

Both Hodgkin and non-Hodgkin lymphoma can present as mediastinal lymphadenopathy, and clinical and radiological information is vital in diagnosing these disorders. ${ }^{43}$ Cytologic diagnosis of Hodgkin lymphoma depends on identification of Reed-Sternberg (RS) cells and their variants, which are not always present. In fact, classic RS cells are rarely seen in cytology smears. ${ }^{98,99}$ One clue in diagnosing Hodgkin lymphoma is the presence of a significant number of eosinophils. When in doubt, excisional biopsy should be performed to reach a definitive diagnosis. High-grade non-Hodgkin

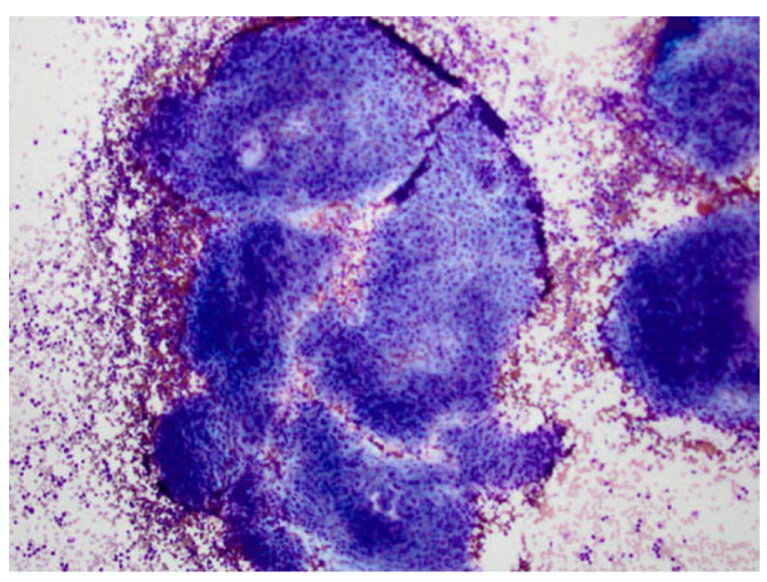

Figure 8 Reactive lymphoid components.

Notes: Large fragments of lymphoid components mimic epithelial cells. Careful examination of the cells at periphery confirms lymphoid origin. lymphoma, such as diffuse large B-cell lymphoma, does not usually pose problems except when it occasionally needs to be distinguished from a poorly differentiated carcinoma. Lowgrade lymphomas, such as small lymphocytic lymphoma, do pose significant challenges in cytology. The presence of a monotonous population of small lymphocytes and absence of germinal center components are probably the most common cytologic features of low-grade lymphomas and should warrant further investigation, including flow cytometry and immunocytochemical studies.

\section{Rare primary and metastatic malignancies}

Rarely, mesothelioma can present as a mediastinal mass with involvement of the regional lymph nodes. ${ }^{100,101}$ With proper clinical history, mesothelioma should be suspected when an FNA sample contains predominantly a discohesive population of pleomorphic polygonal malignant cells with moderate nuclear-to-cytoplasmic ratios and some degree of bi- and multinucleation. A panel of immunocytochemical stains, including TTF-1, napsin A, calretinin, CK5/6, p63, and S-100, may be helpful in distinguishing mesothelioma from other tumors that share similar morphology. Metastatic breast cancers, especially lobular carcinomas, can mimic lymphoid cells and be readily overlooked. ${ }^{102}$ The tumor cells can present as small cells with bland-appearing round-tooval-shaped nuclei and scant cytoplasm (Figure 9). Unlike lymphocytes, however, the tumor cells have rigid nuclear membranes and do not show nuclear molding and crushing artifact. Melanoma is a well-known mimic of many tumors,

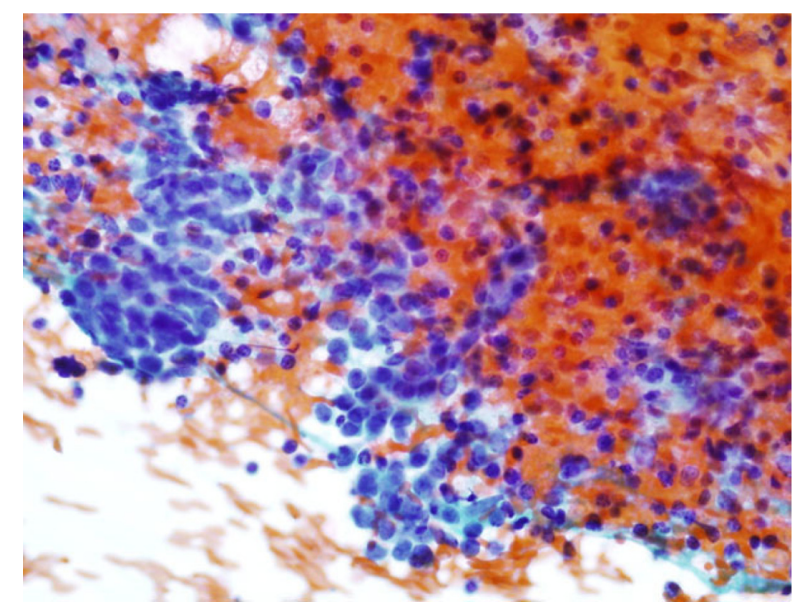

Figure 9 Metastatic breast cancer.

Notes: The sample was taken from a mediastinal lymph node in a patient with a history of breast lobular carcinoma. The tumor cells with small hyperchromatic nuclei and scant cytoplasm are present in single and loosely cohesive clusters, mimicking lymphocytes. 
including lymphomas. Therefore, particular attention should be paid when examining suspected lymph nodes in patients with a history of breast cancer or melanoma. Obtaining sufficient material for cell block and immunocytochemical studies will be very important in these cases.

\section{Conclusion}

In summary, EBUS-FNA is a minimally invasive procedure that can be used to simultaneously diagnose, stage, and obtain cellular material for ancillary studies. Because the main target of EBUS-FNA is the mediastinal lymph node, special attention should be paid to the tumors that morphologically mimic benign lymphocytes, or vice versa. Obtaining adequate samples is essential in reducing false-negative cases. ROSE plays an important role in triaging samples and facilitating sufficient material for cell block.

\section{Disclosure}

The authors report no conflicts of interest in this work.

\section{References}

1. Malvezzi M, Bertuccio P, Rosso T, et al. European cancer mortality predictions for the year 2015: does lung cancer have the highest death rate in EU women? Ann Oncol. 2015;26(4):779-786.

2. Torre LA, Bray F, Siegel RL, Ferlay J, Lortet-Tieulent J, Jemal A. Global cancer statistics, 2012. CA Cancer J Clin. 2015;65:87-108.

3. Cancer. AJCo. AJCC Cancer Staging Manual. 7th ed. New York, NY: Springer; 2009.

4. Shannon JJ, Bude RO, Orens JB, et al. Endobronchial ultrasound-guided needle aspiration of mediastinal adenopathy. Am J Respir Crit Care Med. 1996;153:1424-1430.

5. Annema JT, van Meerbeeck JP, Rintoul RC, et al. Mediastinoscopy vs endosonography for mediastinal nodal staging of lung cancer: a randomized trial. JAMA. 2010;304:2245-2252.

6. Herth FJ, Eberhardt R, Vilmann P, Krasnik M, Ernst A. Real-time endobronchial ultrasound guided transbronchial needle aspiration for sampling mediastinal lymph nodes. Thorax. 2006;61:795-798.

7. Yasufuku K, Pierre A, Darling G, et al. A prospective controlled trial of endobronchial ultrasound-guided transbronchial needle aspiration compared with mediastinoscopy for mediastinal lymph node staging of lung cancer. J Thorac Cardiovasc Surg. 2011;142(1393-1400):e1391.

8. Collins BT. Endobronchial ultrasound fine-needle aspiration biopsy of pulmonary non-small cell carcinoma with subclassification by immunohistochemistry panel. Cancer Cytopathol. 2013;121:146-154.

9. Alsharif M, Andrade RS, Groth SS, Stelow EB, Pambuccian SE. Endobronchial ultrasound-guided transbronchial fine-needle aspiration: the University of Minnesota experience, with emphasis on usefulness, adequacy assessment, and diagnostic difficulties. Am J Clin Pathol. 2008;130:434-443.

10. Wallace WA, Rassl DM. Accuracy of cell typing in non-small cell lung cancer by EBUS/EUS - FNA cytology samples. Eur Respir J. 2011; 38(4):911-917.

11. Silvestri GA, Gonzalez AV, Jantz MA, et al. Methods for staging nonsmall cell lung cancer: diagnosis and management of lung cancer, 3rd ed: American College of Chest Physicians evidence-based clinical practice guidelines. Chest. 2013;143:211S-250S.

12. De Leyn P, Dooms C, Kuzdzal J, et al. Revised ESTS guidelines for preoperative mediastinal lymph node staging for non-small-cell lung cancer. Eur J Cardiothorac Surg. 2014;45(5):787-798.
13. Rusch VW, Asamura H, Watanabe H, Giroux DJ, Rami-Porta R, Goldstraw P. The IASLC lung cancer staging project: a proposal for a new international lymph node map in the forthcoming seventh edition of the TNM classification for lung cancer. J Thorac Oncol. 2009;4:568-577.

14. Detterbeck FC, Postmus PE, Tanoue LT. The stage classification of lung cancer: diagnosis and management of lung cancer, 3rd ed: American College of Chest Physicians evidence-based clinical practice guidelines. Chest. 2013;143:191S-210S.

15. Groth SS, Whitson BA, Maddaus MA. Radiographic staging of mediastinal lymph nodes in non-small cell lung cancer patients. Thorac Surg Clin. 2008;18:349-361.

16. Shrager JB. Mediastinoscopy: still the gold standard. Ann Thorac Surg. 2010;89:S2084-S2089.

17. Defranchi SA, Edell ES, Daniels CE, et al. Mediastinoscopy in patients with lung cancer and negative endobronchial ultrasound guided needle aspiration. Ann Thorac Surg. 2010;90:1753-1757.

18. Hurter T, Hanrath P. Endobronchial sonography: feasibility and preliminary results. Thorax. 1992;47:565-567.

19. Goldberg BB, Steiner RM, Liu JB, et al. US-assisted bronchoscopy with use of miniature transducer-containing catheters. Radiology. 1994;190:233-237.

20. Gasparini S. It is time for this 'ROSE' to flower. Respiration. 2005;72: 129-131.

21. Ernst A, Anantham D, Eberhardt R, Krasnik M, Herth FJ. Diagnosis of mediastinal adenopathy-real-time endobronchial ultrasound guided needle aspiration versus mediastinoscopy. J Thorac Oncol. 2008;3:577-582.

22. Anraku M, Pierre AF, Nakajima T, et al. Endobronchial ultrasound-guided transbronchial needle aspiration in the management of previously treated lung cancer. Ann Thorac Surg. 2011;92:251-255. [discussion 255].

23. von Bartheld MB, Versteegh MI, Braun J, Willems LN, Rabe KF, Annema JT. Transesophageal ultrasound-guided fine-needle aspiration for the mediastinal restaging of non-small cell lung cancer. $J$ Thorac Oncol. 2011;6:1510-1515.

24. Stigt JA, Oostdijk AH, Timmer PR, Shahin GM, Boers JE, Groen HJ. Comparison of EUS-guided fine needle aspiration and integrated PET-CT in restaging after treatment for locally advanced non-small cell lung cancer. Lung Cancer. 2009;66:198-204.

25. Herth FJ, Annema JT, Eberhardt R, et al. Endobronchial ultrasound with transbronchial needle aspiration for restaging the mediastinum in lung cancer. J Clin Oncol. 2008;26:3346-3350.

26. Nasir BS, Bryant AS, Minnich DJ, Wei B, Dransfield MT, Cerfolio RJ. The efficacy of restaging endobronchial ultrasound in patients with non-small cell lung cancer after preoperative therapy. Ann Thorac Surg. 2014;98:1008-1012.

27. Annema JT, Veselic M, Versteegh MI, Willems LN, Rabe KF. Mediastinal restaging: EUS-FNA offers a new perspective. Lung Cancer. 2003;42: 311-318.

28. Popper HH, Ryska A, Timar J, Olszewski W. Molecular testing in lung cancer in the era of precision medicine. Transl Lung Cancer Res. 2014;3:291-300.

29. Travis WD, Brambilla E, Noguchi M, et al. International association for the study of lung cancer/American thoracic society/European respiratory society international multidisciplinary classification of lung adenocarcinoma. J Thorac Oncol. 2011;6:244-285.

30. Folch E, Yamaguchi N, VanderLaan PA, et al. Adequacy of lymph node transbronchial needle aspirates using convex probe endobronchial ultrasound for multiple tumor genotyping techniques in non-small-cell lung cancer. J Thorac Oncol. 2013;8:1438-1444.

31. Schuurbiers OC, Looijen-Salamon MG, Ligtenberg MJ, van der Heijden HF. A brief retrospective report on the feasibility of epidermal growth factor receptor and KRAS mutation analysis in transesophageal ultrasound- and endobronchial ultrasound-guided fine needle cytological aspirates. J Thorac Oncol. 2010;5:1664-1667.

32. Nakajima T, Yasufuku K, Nakagawara A, Kimura H, Yoshino I. Multigene mutation analysis of metastatic lymph nodes in non-small cell lung cancer diagnosed by endobronchial ultrasound-guided transbronchial needle aspiration. Chest. 2011;140:1319-1324. 
33. Billah S, Stewart J, Staerkel G, Chen S, Gong Y, Guo M. EGFR and KRAS mutations in lung carcinoma: molecular testing by using cytology specimens. Cancer Cytopathol. 2011;119:111-117.

34. Reynolds JP, Tubbs RR, Minca EC, et al. EGFR mutational genotyping of liquid based cytology samples obtained via fine needle aspiration (FNA) at endobronchial ultrasound of non-small cell lung cancer (NSCLC). Lung Cancer. 2014;86(2):158-163.

35. Neat MJ, Foot NJ, Hicks A, et al. ALK rearrangements in EBUS-derived transbronchial needle aspiration cytology in lung cancer. Cytopathology. 2013;24:356-364.

36. Ko HM, da Cunha Santos G, Darling G, et al. Diagnosis and subclassification of lymphomas and non-neoplastic lesions involving mediastinal lymph nodes using endobronchial ultrasound-guided transbronchial needle aspiration. Diagn Cytopathol. 2013;41:1023-1030.

37. Lange TJ, Kunzendorf F, Pfeifer M, Arzt M, Schulz C. Endobronchial ultrasound-guided transbronchial needle aspiration in routine care - plenty of benign results and follow-up tests. Int J Clin Pract. 2012;66: 438-445.

38. Ribeiro C, Oliveira A, Neves S, et al. Diagnosis of sarcoidosis in the endobronchial ultrasound-guided transbronchial needle aspiration era. Revista Portuguesa de Pneumologia (English Edition). 2014;20:237-241.

39. von Bartheld MB, Dekkers OM, Szlubowski A, et al. Endosonography vs conventional bronchoscopy for the diagnosis of sarcoidosis: the GRANULOMA randomized clinical trial. JAMA. 2013;309: 2457-2464.

40. Yang B, Li F, Shi W, et al. Endobronchial ultrasound-guided transbronchial needle biopsy for the diagnosis of intrathoracic lymph node metastases from extrathoracic malignancies: a meta-analysis and systematic review. Respirology. 2014;19:834-841.

41. Caraway NP. Strategies to diagnose lymphoproliferative disorders by fine-needle aspiration by using ancillary studies. Cancer. 2005;105: $432-442$.

42. Young NA, Moriarty AT, Haja JC, Wilbur DC. Fine-needle aspiration biopsy of lymphoproliferative disorders - interpretations based on morphologic criteria alone: results from the College of American Pathologists Interlaboratory Comparison Program in Nongynecologic Cytopathology. Arch Pathol Lab Med. 2006;130:1766-1771.

43. Marshall CB, Jacob B, Patel S, et al. The utility of endobronchial ultrasound-guided transbronchial needle aspiration biopsy in the diagnosis of mediastinal lymphoproliferative disorders. Cancer Cytopathol. 2011;119:118-126.

44. Kitamura A, Takiguchi Y, Kurosu K, et al. Feasibility of cytological diagnosis of sarcoidosis with endobronchial US-guided transbronchial aspiration. Sarcoidosis Vasc Diffuse Lung Dis. 2012;29:82-89.

45. Gupta D, Dadhwal DS, Agarwal R, Gupta N, Bal A, Aggarwal AN. Endobronchial ultrasound-guided transbronchial needle aspiration vs conventional transbronchial needle aspiration in the diagnosis of sarcoidosis. Chest. 2014;146:547-556.

46. Sun J, Yang H, Teng J, et al. Determining factors in diagnosing pulmonary sarcoidosis by endobronchial ultrasound-guided transbronchial needle aspiration. Ann Thorac Surg. 2015;99:441-445.

47. Dziedzic DA, Peryt A, Orlowski T. The role of EBUS-TBNA and standard bronchoscopic modalities in the diagnosis of sarcoidosis. Clin Respir J. Epub 2015 Apr 27.

48. Tremblay A, Stather DR, Maceachern P, Khalil M, Field SK. A randomized controlled trial of standard vs endobronchial ultrasonographyguided transbronchial needle aspiration in patients with suspected sarcoidosis. Chest. 2009;136:340-346.

49. Agarwal R, Srinivasan A, Aggarwal AN, Gupta D. Efficacy and safety of convex probe EBUS-TBNA in sarcoidosis: a systematic review and meta-analysis. Respir Med. 2012;106:883-892.

50. Cameron SE, Andrade RS, Pambuccian SE. Endobronchial ultrasoundguided transbronchial needle aspiration cytology: a state of the art review. Cytopathology. 2010;21:6-26.

51. VanderLaan PA, Wang HH, Majid A, Folch E. Endobronchial ultrasound-guided transbronchial needle aspiration (EBUS-TBNA): an overview and update for the cytopathologist. Cancer Cytopathol. 2014;122:561-576.
52. Figueiredo VR, Jacomelli M, Rodrigues AJ, Canzian M, Cardoso PF, Jatene FB. Current status and clinical applicability of endobronchial ultrasound-guided transbronchial needle aspiration. $J$ Bras Pneumol. 2013;39:226-237.

53. Zhang R, Ying K, Shi L, Zhang L, Zhou L. Combined endobronchial and endoscopic ultrasound-guided fine needle aspiration for mediastinal lymph node staging of lung cancer: a meta-analysis. Eur J Cancer. 2013;49:1860-1867.

54. Tanner NT, Silvestri GA. Simultaneously diagnosing and staging lung cancer: a win-win for the patient and the health-care system. Chest. $2013 ; 144: 1747-1748$

55. Baker JJ, Solanki PH, Schenk DA, Van Pelt C, Ramzy I. Transbronchial fine needle aspiration of the mediastinum. Importance of lymphocytes as an indicator of specimen adequacy. Acta Cytol. 1990;34: 517-523.

56. Davenport RD. Rapid on-site evaluation of transbronchial aspirates. Chest. 1990;98:59-61.

57. Feller-Kopman D, Yung RC, Burroughs F, Li QK. Cytology of endobronchial ultrasound-guided transbronchial needle aspiration: a retrospective study with histology correlation. Cancer. 2009;117:482-490.

58. Kramer H, Sanders J, Post WJ, Groen HJ, Suurmeijer AJ. Analysis of cytological specimens from mediastinal lesions obtained by endoscopic ultrasound-guided fine-needle aspiration. Cancer. 2006;108: 206-211.

59. Skov BG, Baandrup U, Jakobsen GK, et al. Cytopathologic diagnoses of fine-needle aspirations from endoscopic ultrasound of the mediastinum: reproducibility of the diagnoses and representativeness of aspirates from lymph nodes. Cancer. 2007;111:234-241.

60. Nayak A, Sugrue C, Koenig S, Wasserman PG, Hoda S, Morgenstern NJ. Endobronchial ultrasound-guided transbronchial needle aspirate (EBUS-TBNA): a proposal for on-site adequacy criteria. Diagn Cytopathol. 2012;40:128-137.

61. Karunamurthy A, Cai G, Dacic S, Khalbuss WE, Pantanowitz L, Monaco SE. Evaluation of endobronchial ultrasound-guided fine-needle aspirations (EBUS-FNA): correlation with adequacy and histologic follow-up. Cancer Cytopathol. 2014;122:23-32.

62. Whitson BA, Groth SS, Odell DD, et al. True negative predictive value of endobronchial ultrasound in lung cancer: are we being conservative enough? Ann Thorac Surg. 2013;95:1689-1694.

63. Gasparini S, Bonifazi M. Rapid on-site cytological evaluation of transbronchial needle aspiration: Why not? Lung India. 2014;31:203-204.

64. da Cunha Santos G, Ko HM, Saieg MA, Geddie WR. "The petals and thorns" of ROSE (rapid on-site evaluation). Cancer Cytopathol. 2013;121:4-8.

65. Nakajima T, Yasufuku K, Saegusa F, et al. Rapid on-site cytologic evaluation during endobronchial ultrasound-guided transbronchial needle aspiration for nodal staging in patients with lung cancer. Ann Thorac Surg. 2013;95:1695-1699.

66. Collins BT, Chen AC, Wang JF, Bernadt CT, Sanati S. Improved laboratory resource utilization and patient care with the use of rapid on-site evaluation for endobronchial ultrasound fine-needle aspiration biopsy. Cancer Cytopathol. 2013;121:544-551.

67. Monaco SE, Schuchert MJ, Khalbuss WE. Diagnostic difficulties and pitfalls in rapid on-site evaluation of endobronchial ultrasound guided fine needle aspiration. Cytojournal. 2010;7:9.

68. Yasufuku K, Fleury Feith J. Cytological specimens obtained by endobronchial ultrasound-guided transbronchial needle aspiration: sample handling and role of rapid on-site evaluation. Ann Pathol. 2012;32: e35-e46.

69. Trisolini R, Cancellieri A, Tinelli C, et al. Rapid on-site evaluation of transbronchial aspirates in the diagnosis of hilar and mediastinal adenopathy: a randomized trial. Chest. 2011;139:395-401.

70. Mehta AC, Cicenia J. ROSEs are read. Chest. 2014;145:7-9.

71. Schmidt RL, Witt BL, Lopez-Calderon LE, Layfield LJ. The influence of rapid onsite evaluation on the adequacy rate of fine-needle aspiration cytology: a systematic review and meta-analysis. Am J Clin Pathol. 2013;139:300-308. 
72. Yarmus L, Van der Kloot T, Lechtzin N, Napier M, Dressel D, FellerKopman D. A randomized prospective trial of the utility of rapid on-site evaluation of transbronchial needle aspirate specimens. J Bronchology Interv Pulmonol. 2011;18:121-127.

73. Layfield LJ, Bentz JS, Gopez EV. Immediate on-site interpretation of fine-needle aspiration smears: a cost and compensation analysis. Cancer. 2001;93:319-322.

74. Medford AR, Pillai A. Cytotechnician rapid on-site evaluation for cytology for transbronchial needle aspiration. J Bronchology Interv Pulmonol. 2013;20:189-190.

75. Bonifazi M, Sediari M, Ferretti M, et al. The role of the pulmonologist in rapid on-site cytologic evaluation of transbronchial needle aspiration: a prospective study. Chest. 2014;145:60-65.

76. McCarthy EE, McMahon RQ, Das K, Stewart J 3rd. Internal validation testing for new technologies: bringing telecytopathology into the mainstream. Diagn Cytopathol. 2015;43:3-7.

77. Alsharif M, Carlo-Demovich J, Massey C, et al. Telecytopathology for immediate evaluation of fine-needle aspiration specimens. Cancer Cytopathol. 2010;118:119-126.

78. Khurana KK, Kovalovsky A, Wang D, Lenox R. Feasibility of dynamic telecytopathology for rapid on-site evaluation of endobronchial ultrasound-guided transbronchial fine needle aspiration. Telemed $J E$ Health. 2013;19:265-271.

79. Trisolini R, Cancellieri A, Tinelli C, et al. Randomized trial of endobronchial ultrasound-guided transbronchial needle aspiration with and without rapid on-site evaluation for lung cancer genotyping. Chest. Epub 2015 Jul 9.

80. Wahidi MM, Hulett C, Pastis N, et al. Learning experience of linear endobronchial ultrasound among pulmonary trainees. Chest. 2014;145: 574-578.

81. Park WY, Kim MH, Shin DH, et al. Ciliated adenocarcinomas of the lung: a tumor of non-terminal respiratory unit origin. Mod Pathol. 2012;25:1265-1274

82. Policarpio-Nicolas ML, Wick MR. False-positive interpretations in respiratory cytopathology: exemplary cases and literature review. Diagn Cytopathol. 2008;36:13-19.

83. Thivolet-Bejui F. Cytological pitfalls in bronchopulmonary tumors. Diagn Cytopathol. 1997;17:412-416.

84. Sheikh HA, Fuhrer K, Cieply K, Yousem S. p63 expression in assessment of bronchioloalveolar proliferations of the lung. Mod Pathol. 2004; 17:1134-1140.

85. Fritscher-Ravens A, Ghanbari A, Topalidis T, et al. Granulomatous mediastinal adenopathy: can endoscopic ultrasound-guided fine-needle aspiration differentiate between tuberculosis and sarcoidosis? Endoscopy. 2011;43:955-961.

86. Gailey MP, Keeney ME, Jensen CS. A cytomorphometric analysis of pulmonary and mediastinal granulomas: differentiating histoplasmosis from sarcoidosis by fine-needle aspiration. Cancer Cytopathol. 2015;123:51-58.

87. Rosen Y. Four decades of necrotizing sarcoid granulomatosis: what do we know now? Arch Pathol Lab Med. 2015;139:252-262.
88. Ren Y, Raitz EN, Lee KR, Pingleton SK, Tawfik O. Pulmonary small lymphocytic lymphoma (mucosa-associated lymphoid tissue type) associated with pulmonary hyalinizing granuloma. Chest. 2001;120: 1027-1030.

89. O'Connell MJ, Schimpff SC, Kirschner RH, Abt AB, Wiernik PH. Epithelioid granulomas in Hodgkin disease. A favorable prognostic sign? JAMA. 1975;233:886-889.

90. Reddy CR, Rajakumari K, Jayasimha P. Keratin granulomas in squamous cell carcinomas treated by irradiation. Indian J Cancer. 1975; 12:327-333.

91. Richter HJ, Leder LD. Lymph node metastases with PAS-positive tumor cells and massive epithelioid granulomatous reaction as diagnostic clue to occult seminoma. Cancer. 1979;44:245-249.

92. Brincker H. Sarcoid reactions in malignant tumours. Cancer Treat Rev. 1986;13:147-156.

93. Ophir D, Nissim F, Marshak G. Granulomatous reaction in lymph nodes draining laryngeal carcinoma. Head Neck Surg. 1986;8:214-217.

94. Heffner JE, Milam MG. Sarcoid-like hilar and mediastinal lymphadenopathy in a patient with metastatic testicular cancer. Cancer. 1987;60: 1545-1547.

95. Yamada S, Noguchi H, Nabeshima A, et al. Basaloid carcinoma of the lung associated with central cavitation: a unique surgical case focusing on cytological and immunohistochemical findings. Diagn Pathol. 2012;7:175.

96. Maleki Z. Diagnostic issues with cytopathologic interpretation of lung neoplasms displaying high-grade basaloid or neuroendocrine morphology. Diagn Cytopathol. 2011;39:159-167.

97. Crapanzano JP, Loukeris K, Borczuk AC, Saqi A. Cytological, histological, and immunohistochemical findings of pulmonary carcinomas with basaloid features. Diagn Cytopathol. 2011;39: 92-100.

98. Das DK. Cytopathology: 1c06-1 Hodgkin lymphoma: diagnostic criteria and pitfalls. Pathology. 2014;46(Supp1 2):S9.

99. Das DK. Value and limitations of fine-needle aspiration cytology in diagnosis and classification of lymphomas: a review. Diagn Cytopathol. 1999;21:240-249.

100. Bruno P, Pisani L, Ricci A, et al. Cytology on transbronchial needle aspiration (TBNA): not only for lung cancer. Anticancer Res. 2010;30:4769-4772.

101. Hamamoto J, Notsute D, Tokunaga K, et al. Diagnostic usefulness of endobronchial ultrasound-guided transbronchial needle aspiration in a case with malignant pleural mesothelioma. Intern Med. 2010;49:423-426.

102. Sanz-Santos J, Cirauqui B, Sanchez E, et al. Endobronchial ultrasoundguided transbronchial needle aspiration in the diagnosis of intrathoracic lymph node metastases from extrathoracic malignancies. Clin Exp Metastasis. 2013;30:521-528.

103. Smithius R. IASLC lymph node map 2009. Radiology Assistant. Available at: http://www.radiologyassistant.nl/en/p4646f1278c26f/ mediastinum-lymph-node-map.html. Accessed May 7, 2015.
Pathology and Laboratory Medicine International

\section{Publish your work in this journal}

Pathology and Laboratory Medicine International is a peer-reviewed, open access journal focusing on innovative basic research and translational research related to pathology or human disease. The journal includes original research, updates, case reports, reviews and commentaries on current controversies. The Academic Sponsor

\section{Dovepress}

of this journal is the Chinese American Pathology Association (CAPA). The manuscript management system is completely online and includes a very quick and fair peer-review system. Visit http://www.dovepress.com/testimonials.php to read real quotes from published authors. 